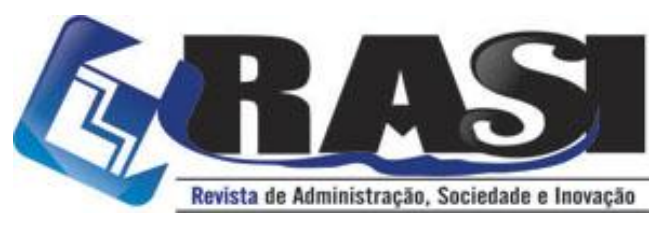

http://www.rasi.vr.uff.br

RASI, Volta Redonda/RJ, v. 7, n. 1, pp. 70-83, Jan./Abr. 2021

\title{
Um Retrato das Startups de uma Aceleradora Localizada em Belo Horizonte, Minas Gerais
}

\author{
Bárbara Graciano de Oliveira (UFMG) - gracioliv.barbara@gmail.com \\ Cíntia Siqueira Araújo Soares (IFMG) - cintiasoares2007@ gmail.com \\ Cristina Luiza Ramos da Fonseca (UFMG e FIOCRUZ) - cristinaluiza@ gmail.com \\ Allan Claudius Queiroz Barbosa (UFMG) - allan@ufmg.br
}

\begin{abstract}
Resumo:
A renovação e o desenvolvimento de uma economia dependem da inovação, que muito se relaciona com novos empreendimentos e startups. Este artigo tem por objetivo caracterizar as startups existentes no ecossistema de inovação de Belo Horizonte (Minas Gerais), considerando aquelas participantes em um Programa de Aceleração. Para tanto, adotou-se a pesquisa qualitativa com abordagem descritiva e estudo de caso com enfoque no Programa de Aceleração da Techmall S.A. Pela pesquisa realizada, foi possível constatar que o perfil do empreendedor é predominantemente de jovens, sem vivência empreendedora anterior, com formação em ciências exatas. Quanto às Startups, a maioria está em fase de operação em diversos segmentos; receberam algum prêmio, e não são resultados de spin-offs acadêmicas ou empresariais. A forma predominante de contratação de seus colaboradores é por estágio temporário e por regime de bolsa. Foi possível verificar que seus principais desafios são osde escalar venda e de captar cliente (desafios internos), alémde obter capital inicial, financiamentos e investimentos (desafios externos). Para enfrentar tais desafios, a aceleradora deveria auxiliar no mapeamento de clientes e na determinação de estratégias para vendas, considerando que isso é uma das dificuldades apresentadas. Por fim, o estudo conclui que é preciso que o Ecossistema de Inovação Mineiro esteja atento aos desafios encontrados, de modo a formular políticas para minimizá-los.
\end{abstract}

Palavras-Chave: Empreendedorismo; Inovação; Startups.

\section{The Profile of the Startups of an Accelerator Located in Belo Horizonte, Minas Gerais}

\begin{abstract}
:
The renewal and development of an economy depend on innovation, which is closely related to new ventures and startups. This article aims to characterize existing startups in the innovation ecosystem of Belo Horizonte (Minas Gerais - Brazil), considering the startups present in an Acceleration Program. For achieving this purpose, a qualitative research with a descriptive approach and a case study focusing on the Techmall S.A. Acceleration Program was adopted. The results revealed the profile of the entrepreneur, predominantly young, without previous entrepreneurial experience and with degree in Exact Sciences. As for Startups, most are in operation in several segments; received some award and are not aresult of academic or business spin-offs. The predominant form of hiring employees is temporary internship and scholarship regime. The results presented the main challenges faced by the startups are escalating sales and attracting customers (internal challenges), and taking initial capital, financing and foreign investments (external challenges). To face such challenges, the accelerator should assist in mapping customers and determining sales strategies, considering that this is one of the difficulties found. Finally, the study concluded that it is necessary that the Minas Gerais Innovation Ecosystem be aware of the challenges encountered, in order to formulate policies to minimize them.
\end{abstract}

Keywords: Entrepreneurship; Innovation; Startups.

\section{Universidade \\ Fluminense}

R. Desembargador Ellis Hermydio Figueira, 783, Bloco A, sl. 218, Aterrado. 27213-415 - Volta Redonda, RJ - Brasil

www.uff.br

Copyright ( 92020 RASI. Todos os direitos, até mesmo de tradução, são reservados. É permitido citar parte de artigos sem autorização prévia, desde que seja identificada a fonte. 


\section{Um Retrato das Startups de uma Aceleradora Localizada em Belo Horizonte, Minas Gerais}

\section{Introdução}

Atualmente, startups são as maiores fontes de inovação, por isso as corporações têm se aproximado destartups para obter inovações externas (Kohler, 2016). Por outro lado, em um contexto que sugere a relevância do empreendedorismo para alavancar o crescimento econômico do país, é preciso buscar investidores e gerar novas tecnologias, emprego e renda (Nogami, 2019).Inovar e transformar insights em oportunidades para geração de novos modelos de negócios são pontos cruciais para a criação de startups(principal ativo intangível das organizações que têm foco no conhecimento). Justifica-se, então, a importância das startups pelo fato de encabeçarem grandes inovações substituidoras de tecnologias e de modelos de negócios (Kohler, 2016); e por estarem se avultando no cenário econômico pela facilidade e pela rapidez com que escalonam a inovação (Weiblen, \& Chesbrough, 2015).

Ressalta-se que há um grande risco de insucesso nesse tipo de empreendimento, pois $25 \%$ das startups sobrevivem até um ano de vida, enquanto $50 \%$ delas mantêm as atividades apenas por até quatro anos e $75 \%$ finalizam suas operações em até treze anos (Nogueira, \& Arruda, 2015). Dessa forma, é preciso mapear quais são seus os principais desafios a fim de mitigá-los e garantir a sustentabilidade desse tipo empreendimento (Nogami, 2019).

O estudo do perfil das startups ganha preponderânciap elo fervor do movimento empreendedor direcionado à inovação, relevante para o crescimento econômico (Teixeira, 2007; Cusumano, 2013). Entretanto, para que empreendimento desse tipo se desenvolva, é preciso que o ecossistema de inovação seja apropriado para promover conexões e fomentar a educação empreendedora (Abstart-Ups, 2017; Armanios, 2017).

Nesse ecossistema, há uma grande variedade de formatos que podem ser adotados pelas aceleradoras, que vão desde a existência ou não de espaço de coworking, até o tempo de extensão do programa, passando por tipos de atores filiados, como firmas de capital de risco ou universidades locais; o que faz com que seus resultados sejam pouco claros (Cohen, \& Hochberg, 2014). Deste modo, os efeitos de programas de aceleração podem ser variados (Cohen, et al., 2019), exigindo adaptações de práticas ao seu perfil.

A Techmall S.A. é uma aceleradora mineira que está entre as dez maiores do Brasil e já acelerou aproximadamente 400 startups. Neste contexto, o objetivo principal deste artigo é caracterizar as startups presentes no Programa de Aceleração de Empresas Techmall S.A., de modo a subsidiar a elaboração de ações internas e de políticas públicas para a melhoria do ambiente inovador de Belo Horizonte, terceira cidade do Brasil em número de startups (Matos, 2017). A pesquisa teve como objetivos específicos identificar composição e estrutura da iniciativa; definir características das startups; e entender desafios enfrentados.

O presente estudo, além desta introdução, está organizado em outras seções. A seguir, discutimos o referencial teórico abordando brevemente conceitos relacionados as startups e aceleradoras. Posteriormente, encontram-se expostos os procedimentos metodológicos seguidos na investigação, a análise e a discussão dos resultados e, por fim, as considerações finais. 


\section{Referencial Teórico}

A seguir, serão apresentados, brevemente, os significados de startups (conceito e fases) e de aceleradoras (importância e diferença para incubadoras). Considera-se que esses são conceitos chaves para compreensão de resultados e sua discussão.

\subsection{Breve Contextualização das Startups}

O termo startups começou a ser usado no Brasil em 1999, em plataformas virtuais de comercialização de produtos (Dornelas, 2016; SEBRAE, 2018). As Startups podem ser conceituadas como organizações em fase inicial, que se localizam em panoramas de incerteza e que possuem modelos de negócios focalizados na inovação em produtos ou serviços, com a finalidade de ofertá-los como solução para demandas latentes de mercado, inserindo-se em novos campos de atuação (SEBRAE, 2018). As startups, portanto, criam soluções que sejam repetíveis e escaláveis, com potencial de alto crescimento (Abstart-Ups, 2017).

As startups podem ser consideradas como negócios de alto risco que são capazes de validar e de aprimorar, de forma rápida, seus modelos de negócios a ponto de poderem sobrepujar as incertezas do seu ambiente (Perin, 2015). Ademais, as startups estão altamente conectadas com o empreendedorismo e a inovação (Ries, 2011). Mesmo sendo as startups definidas como negócios nascentes (Salamzadech, \& Kesim, 2015), não são todos os empreendimentos em fases iniciais que podem ser conceituados como startups (Acs, \& Amóros, 2008). Apenas os que objetivam transformar ideias em negócios viáveis em um ambiente incerto e volátil são startups (Radojevich-Kelley, \& Hoffman, 2012; Ries, 2011).

Em relação ao nível de desenvolvimento, há diversos modelos teóricos que definem estágios de start up. Entre tais modelos, há o do SEBRAE (2018), o de Abernathy e Utterback (1978) e o de Vohora et al. (2004). Para fins desse estudo, será adotado o modelo do SEBRAE (2018), uma vez que é o utilizado na Aceleradora Techmall S.A. Por esse modelo, classificam-se as Startups em quatro estágios (SEBRAE, 2018):

- ideação: desenvolvimento da ideia - realização do estudo do mercado, identificação de oportunidades, nichos e soluções;

- operação: protótipos validados- modelo de negócio definido e mercado conhecido, sendo iniciadas as operações do negócio;

- tração: indicadores de mensuração e objetivos definidos - começo da busca por parcerias para crescimento;

- scale up ou escalonamento: crescimento expressivo do negócio - aumento de demanda, financiamento do negócio, novas contratações e melhoria dos processos.

Em complemento aos estágios mencionados, as startups possuem estrutura organizacional simples, e o empreendedor está muito envolvido com o negócio, centralizando diversas funções (Leung, et al., 2006). Nas startups, o foco está na assimilação de oportunidades em negócios duradouros e em manteremos negócios em atividade com os recursos limitados de que dispõem. Vencidos esses desafios, os empreendimentos buscam se consolidar como empresas (Perin, 2015).

É importante salientar que não há um conceito rígido e fechado de startups. Isto pode resultar em uma abordagem interessante, permitindo que diversas empresas se beneficiem do termo, especialmente na construção da imagem no mercado e na captação de recurso, posicionando-se como atraentes ao incorporarem a ideia de startups como forma de trabalho novo, criativo e moderno (Cockayne, 2019).

A relação das startups com a inovação a colocam em ponto de destaque para o desenvolvimento econômico, em especial por sua capacidade de gerar e implementar 
inovação tecnológica de forma ágil (Weiblen, \& Chesbrough, 2015), promovendo a substituição de tecnologias e modelos de negócios por inovações relevantes (Kohler, 2016). Deste modo, as startups desempenham papel relevante na introdução de inovações no mercado e na sua viabilização econômica (Hunt, 2013), em especial, no estágiode tração (SEBRAE, 2018). Essa facilidade pode ser justificada pelos elementos descritos por Kovács (2003) como fundamentais para a inovação e presentes nas startups: poucos níveis hierárquicos, ênfase no trabalho em equipe com alta autonomia, valorização das competências e participação dos colaboradores; relações de trabalho baseadas na confiança; e capacidade de aprendizagem organizacional contínua. Sobre o aprendizado organizacional, Lins Filho, Andrade e Silva (2020) apontam que, nas startups, há uma grande capacidade de aprendizado em decorrência dos modos de compartilhamento de conhecimento intraorganizacional, com mente aberta e comunicação ágil com stakeholders, pois isso está correlacionado com a capacidade de inovar.

Para a consolidação das startups, as aceleradoras constituem uma importante ferramenta, uma vez quetêm a função de auxiliar as startups a atingiram o seu ponto de equilíbrio e obter investimentos que garantam a consolidação dos seus produtos/serviços no mercado (Santos, 2008). Ademais, as aceleradoras disponibilizam, em geral, recurso financeiro próprio para investimento, o chamado Seed Money, ambiente de coworking, que estimula a criação de redes de colaboração e promove oportunidades de capacitação (Cohen et al., 2019).

\subsection{As Aceleradoras}

As aceleradoras surgiram no final de 1980como laboratórios de pesquisa e, somente em 2000, foram reconhecidas como tal quando passaram a ser guiadas por empreendedores bem-sucedidos e mais experientes (O’Connell, 2011). As aceleradoras podem ser definidas como provedoras de serviços que auxiliam as startups na condução de seus negócios, disponibilizando espaço para escritório, mentoria, rede de relacionamento, serviços de gerenciamento, conhecimento, expertise, ajudando na constituição da equipe e no refinamento das ideias até o desenvolvimento do produto final (Radojevich-Kelley, \& Hoffman, 2012).

Ademais, os programas de aceleração fomentam a conexão das startups a possíveis parceiros externos como: investidores e fundos de investimento, ou pesquisadores que podem contribuir para o aprimoramento de produto ou de serviço, ou empresários e mentores de negócio que podem cooperar para o crescimento e a consolidação do empreendimento (Dempwolf, et al., 2014; Startup Brasil, 2018).

As aceleradoras são importantes na busca de recursos financeiros; afinal, como as startups estão em ambiente de grande incerteza e sujeitas a alto risco, dificilmente os seus fundadores irão disponibilizar recursos próprios para o investimento inicial (Machado, 2015). Além disso, as aceleradoras agem em pontos importantes para o sucesso da startup (Stayton, \& Mangematin, 2019):

- na base, para criação e sobrevivência do empreendimento;

- na formação de uma rede de financiamento do negócio; e

- no estabelecimento de conhecimento e demais pontos necessários para que a startup possa competir em pé de igualdade com os concorrentes.

É importante também ressaltar o que difere aceleradoras de incubadoras. Enquanto as primeiras são mais voltadas para o mercado, intensificando a interação dos investidores e compradores com as startups para que se adaptem e aprendam mais rapidamente o funcionamento do mercado, as últimas tendem a auxiliar as empresas inovadoras nos seus 
estágios bem iniciais (Cohen, 2013). Por outro lado, a exemplo do conceito de startup, não há consenso quanto a essa definição, podendo a incubadora também ser classificada como organização com "enfoque (...) [em] criação e acesso às redes para promoção de recursos, conhecimento e legitimidade" (Antunes, Araújo, \& Almeida, 2020, p. 7) ou formas de aceleração do crescimento e aumento do sucesso em startups (Ramírez, et al., 2019).

Como é possível observar, o conceito de aceleradoras se confunde com o de incubadoras, o que pode ser justificado pelo exposto por alguns autores que afirmam que as aceleradoras são uma nova geração de incubadoras (Mian, Lamine, \& Fayolle, 2016). Neste sentido é possível sugerir que empresas do segmento de base tecnológicas e de pequenos serviçosque não exportam possuem mais chances de sucesso por meio da aceleradora, ao passo que as demais deveriam preferir as incubadoras (Del Sarto, Isabelle, \& Di Minin, 2019).

\section{Procedimentos Metodológicos}

Considerando o objetivo deste artigo, adotou-se a pesquisa qualitativa com abordagem descritiva. Trata-se ainda de um estudo de caso (Yin, 1994), visto que se busca compreender, de forma individual as características das startups que compõem os Programas de Aceleração selecionados. Quanto ao lócus da pesquisa, em outubro de 2018, a Techmall S.A. possuía informações acerca de 44 (quarenta e quatro) startups que participaram ou participam dos Programas de Aceleração. Dessas 44 (quarenta e quatro), 30 (trinta) estavam em atividade na época. Das 30 (trinta) startups em atividade, apenas 14 (quatorze) aceitaram participar da pesquisa.

Para coletar os dados, optou-se por um questionário eletrônico, vinculado à ferramenta Google Forms, construído considerando diligência e dinâmica dos CEOs das startups e sua baixa predisposição para preencher formulários impressos ou pouco tempo para participar de entrevista presencial. O questionário usou jargões comuns ao cotidiano do empreendedor, disponibilizando, em alguns casos, o significado de termos específicos para eventuais desconhecimentos. Foi realizado pré-teste para validação das questões. Foi apresentada a versão final do questionário ao CEO da Aceleradora Techmall S.A., para verificar quais informações a aceleradora já possuía e que poderiam ser retiradas do questionário. A aceleradora prontamente apresentou uma planilha com nome de cada startup e do CEO, telefone de contato, e-mail, site e resumo do negócio.

$\mathrm{O}$ instrumento de coleta foi elaborado a partir de cinco categorias: perfil do diretor executivo (CEO), aspectos gerais da startup, características dos recursos humanos envolvidos, desafios, indicadores e inovação, experiência no Programa de Aceleração. O questionário contemplou as cinco categorias supracitadas, totalizando 46 perguntas, sendo 39 de múltipla escolha e 07 discursivas. Ademais, 44 questões eram de resposta compulsória e duas opcionais. $\mathrm{O}$ detalhamento da correlação de cada uma das categorias com as perguntas e os objetivos está descrito no Quadro 1, a seguir. 


\begin{tabular}{|l|l|}
\multicolumn{2}{|c}{ Quadro 1-Descrição das categorias de análise } \\
\hline Categoria & \multicolumn{1}{c|}{ Temas das perguntas } \\
\hline $\begin{array}{l}\text { Perfil do CEO da } \\
\text { (10 perguntas) }\end{array}$ & $\begin{array}{l}\text { Perfil do participante quanto a: faixa etária, estado civil, existência de filhos, } \\
\text { experiência empreendedora em iniciativas anteriores que poderiam ou não ser bem } \\
\text { sucedidas, e formação acadêmica dos fundadores. }\end{array}$ \\
\hline $\begin{array}{l}\text { Aspectos Gerais da } \\
\text { startup } \\
\text { (12 perguntas) }\end{array}$ & $\begin{array}{l}\text { Características da startup quanto a: setor de atuação, data de surgimento, } \\
\text { formalização do CNPJ, grau de maturidade do empreendimento, forma de criação da } \\
\text { startup, fase do empreendimento, participação em algum programa de incubação e } \\
\text { em premiaçães recebidas, além dos desafios enfrentados. }\end{array}$ \\
\hline $\begin{array}{l}\text { Características dos } \\
\text { Recursos Humanos } \\
\text { envolvidos } \\
\text { (8 perguntas) }\end{array}$ & $\begin{array}{l}\text { Identificação das pessoas envolvidas em relação à: gênero dos sócios e sua formação } \\
\text { acadêmica; presença de capacidades relevantes para a área de comércio; gerência e } \\
\text { técnica no início do empreendimento; formação da equipe (número de pessoas e } \\
\text { forma de contratação). }\end{array}$ \\
\hline $\begin{array}{l}\text { Desafios, Indicadores } \\
\text { e Inovação } \\
\text { (11 perguntas) }\end{array}$ & $\begin{array}{l}\text { Mapeamento das principais dificuldades encontradas; concorrência, tipo de inovação } \\
\text { do negócio, forma de propriedade intelectual obtida, produtos ou serviços } \\
\text { desenvolvidos e comercializados, fases de desenvolvimento ou aprimoramento de } \\
\text { novos produtos ou serviços e o faturamento da empresa. }\end{array}$ \\
\hline $\begin{array}{l}\text { Sobre a experiência } \\
\text { no Programa de } \\
\text { Aceleração } \\
\text { (5 perguntas) }\end{array}$ & $\begin{array}{l}\text { Percepção da startup quanto: experiência na participação em um programa de } \\
\text { aceleração, motivos da escolha da Aceleradora Techmall S.A., pontos fortes e fracos } \\
\text { do Programa e desafios referentes ao processo de aceleração. }\end{array}$ \\
\hline
\end{tabular}

Fonte: Elaborado pelos autores (2019).

A planilha enviada pela aceleradora contemplava os dados de 2013 a 2018, tendo, portanto, informações de empresas que não estavam mais ativas, como informado anteriormente. Assim, como a pesquisa estava circunscrita às startups ativas, foi necessário contato telefônico para verificar o status do empreendimento. Nesse contato, após ser verificado que a startup ainda estava em operação, foi apresentada a proposta da pesquisa e solicitada a participação da empresa. Coletaram-se os dados, disponibilizando-se o questionário no período de 09 de outubro a 20 de novembro de 2018.A análise dos dados foi realizada referente às categorias previstas, utilizando-se estatística descritiva. Os resultados estão apresentados na sessão Resultados e Análises deste documento.

\section{Resultados e Análises}

O resultado das 14 startups respondentes permitiu caracterizar o perfil do empreendedor como sendo, em sua maioria, jovens entre 24 a 36 anos $(78,6 \%)$, com idade média de 33 anos. A maioria possui características que remetem ao empreendedorismo, uma vez que os respondentes afirmaram ter iniciado o negócio por interesse próprio. Entretanto, quase metade dos respondentes apresenta alguma experiência de empreendedorismo na família, sendo que, pouco mais da metade (57\%), estão vivenciando, pela primeira vez, uma experiência como empreendedores e $14 \%$ dos entrevistados não tiveram sucesso no empreendimento anterior.

Esses resultados corroboram a tendência de estudos sobre inovação voltados para o papel do empreendedor e sua atuação em empresas familiares (Sousa, et al., 2020). A combinação desses dois dados evidencia que $71 \%$ das pessoas entrevistadas não atingiram o sucesso em alguma vivência empreendedora. Finalmente, outro ponto que completou o perfil é a predominância da formação na área de ciências exatas, com destaque para os cursos de Engenharia (nas suas variações), Desenho Industrial, Ciências da Computação e Ciências da Informação. 
Destaca-se que o perfil do empreendedor é essencial para definição de políticas para o setor de inovação, entendendo que o apoio ao empreendedor é fundamental para o sucesso do processo de pesquisa e desenvolvimento, de inovação e de crescimento econômico do Brasil (Reis, \& Gomes, 2017). O empreendedorismo determina um entendimento do mundo, envolve uma forma de ser e de se relacionar com a realidade. A procura por novas alternativas é um atributo específico do empreendedor (Dolabela, 2008). Além disso, observa-se que a maioria dos respondentes se tornou empreendedor por oportunidade e não por necessidade.

Ao marcarem a opção que afirma que sempre tiveram interesse em construir seu próprio negócio, em vez das opções "não me adaptei à dinâmica do mercado de trabalho como funcionário de uma empresa, e encontrei no empreendedorismo uma opção de carreira" ou "desenvolvo outra atividade paralelamente, e busco no empreendedorismo a oportunidade de complementar minha renda"; fica clara a característica do empreendedorismo por necessidade. Ademais, na área de formação, nota-se que não possuem capacidades gerenciais, posto que sua formação é da área de ciências exatas, corroborando os achados de Armanios et al. (2017) e Kulchina (2017).

Quanto aos aspectos gerais das startups, foram encontradas algumas características relevantes presentes na Tabela 1. Com base nos estágios da startup (SEBRAE, 2018), sete delas então em fase de operações, quatro em fase de tração e três em fase de escalonamento.

Tabela 1 - Estágio no qual as startups se encontram

\begin{tabular}{cccccc}
\hline Estágios & $\mathbf{N}^{\mathbf{0}}$ startups & $\begin{array}{c}\text { Possuem } \\
\text { produto } \\
\text { comercializado }\end{array}$ & Possuem CNPJ & $\begin{array}{c}\text { Possuem } \\
\text { faturamento }\end{array}$ & $\begin{array}{c}\text { Faturamento } \\
\mathbf{2 0 1 7}\end{array}$ \\
\hline Operação & 7 & 4 & 6 & 6 & $\begin{array}{c}\text { até } 100 \text { mil } \\
\text { reais ano }\end{array}$ \\
\hline Tração & 4 & 4 & 4 & 3 & $\begin{array}{c}\text { até } 100 \text { mil } \\
\text { reais ano }\end{array}$ \\
\hline $\begin{array}{c}\text { Escalona- } \\
\text { mento }\end{array}$ & 3 & 3 & 3 & 1 & $\begin{array}{c}\text { até } 100 \text { mil } \\
\text { reais ano }\end{array}$ \\
& & & & 1 & $\begin{array}{c}\text { de } 101 \text { mil a } \\
500 \text { mil reais }\end{array}$ \\
\hline & & & & 1 & $\begin{array}{c}\text { de 501 mil a 1 } \\
\text { milhão de reais }\end{array}$ \\
\hline
\end{tabular}

Fonte: Elaborado pelos autores (2019).

Como é possível observar na Tabela 1, as startups, ainda no estágio de operação, já conseguem obter um faturamento comparável com o faturamento mediano de microempresas pelos valores de maio 2016; ao passo que, no estágio de escalonamento, as startups já se assemelham, em termos de faturamento, a empresas de pequeno porte (SEBRAE, 2016). A maioria das startups possui produtos em fase de comercialização, formalizada com CNPJ.

Com relação aos produtos/serviços das startups, $78,6 \%$ dos produtos ou serviços dos empreendimentos estão sendo comercializados; $14,3 \%$ estão na fase de projeto e desenvolvimento, enquanto $7,1 \%$ ainda estão na fase de conceituação do produto ou serviço. 
Tabela 2 - Produtos e/ou serviços produzidos e comercializados

\begin{tabular}{lcc}
\hline \multicolumn{1}{c}{ Situação } & $\mathrm{N}^{\mathbf{o}}$ startups & Percentual \\
\hline Nenhum & 1 & 7,1 \\
1 & 5 & 35,7 \\
De 2 a 5 & 8 & 57,2 \\
De 6 a 10 & - & - \\
Mais de 10 & - & - \\
\hline
\end{tabular}

Fonte: Elaborado pelos autores (2019).

Além disso, 85,7\% dos entrevistados classificaram as inovações nos seus produtos/ serviços como sendo incrementais. Por outro lado, 57,1\% dos empreendedores possuem de dois a cinco produtos ou serviços desenvolvidos; porém, os demais têm apenas um produto no portfólio. Observa-se que $21,4 \%$ das startups têm propriedade intelectual nas modalidades registro de marca, depósito de patente e registro de software.

É possível destacar ainda que há uma considerável diversidade de segmento de atuação, sendo o principal grupo o de logística e mobilidade urbana, com quatro startups nesse campo. Das quatorze startups pesquisadas, oito dela receberam prêmios, dentre eles:Prêmio 'Connected Smart Cities'; 'Laureate Brasil'; 'ABVCAP'; 'Baanko challenge'; 'TegUp'; '100 Open Startups'; 'Inovativa'; 'Top 10 Startups do Ano'; 'Top 5 Lemonade'; 'Campeão EC'; 'Perestroika'; 'Top 20 Encontre um Anjo'; 'Inovabra'; 'Endeavor Conecta', que, além de promoverem o seu reconhecimento, possibilitam o recebimento de recursos financeiros, um dos seus pontos críticos, como será mostrado a frente.

Quanto ao tempo de existência desde o período de criação da ideia primordial de cada startup, 79\% delas, aproximadamente, estão em vigor há mais de três anos. Assim, a maioria das startups está em funcionamento há mais tempo do que um quarto das pesquisadas por Nogueira e Arruda (2015), que fecham os negócios com menos de um ano. No entanto, ainda que estejam mais consolidadas, $90 \%$ das empresas entendem que ainda são startups.

Constatou-se que mais de $70 \%$ das startups originaram-se distantes de centros de pesquisa e/ou empresas privadas; somente $28,6 \%$ podem ser classificadas como spin-offs ${ }^{I}$ acadêmicas ou empresariais. Em relação ao faturamento, a maioria $(85,7 \%)$ faturou, em 2017 , até 100 mil reais e, para 2018,64,3\% das startups esperam obter rendimentos de até 100 mil reais. Corroborando a caracterização verificada para os empreendedores, averiguou-se que mais de $70 \%$ das startups não participaram, anteriormente, de programas de incubação.

Em relação à direção das organizações estudadas, 92,9\% delas têm dois ou mais sócios. Quanto às características dos sócios, considerando apenas aqueles que estavam no momento de concepção da startup, metade destes empreendimentos $(57,1 \%)$ possuem ou possuíram, no seu início, sócios que apresentavam competências comerciais. A maioria destas startups $(78,6 \%)$ contava com a presença de, ao menos, um sócio com expertise em gestão; concomitantemente, a maioria desses empreendimentos $(78,6 \%)$ iniciou suas operações com ao menos um sócio com experiência técnica. Quanto ao sexo dos sócios, metade das startups possuem ou possuíam mulheres como sócias.

Sobre a equipe das startups, metade possui colaboradores mulheres e a maior parte da contratação é feita por meio de estágio temporário ou regime de bolsas. Essa forma de

\footnotetext{
${ }^{1}$ Processo de formação de um novo empreendimento a partir de um já existente.
} 
contratação pode evidenciar o caráter ainda não consolidado das organizações, uma vez que essas contratações possuem baixa incidência de impostos trabalhistas e o encerramento da contratação de colaboradores é mais simples e flexível para permitir a adequação à demanda ou à situação vivida no período. Entretanto, essas formas de contratação são mais suscetíveis a futuros processos trabalhistas, pois são mais frágeis do que emprego de carteira assinada. Assim, há que se avaliar os riscos e os benefícios dessa prática.

Observou-se que, aproximadamente, metade $(57,1 \%)$ das startups possui entre um a três concorrentes; enquanto $14,3 \%$ têm de quatro a seis concorrentes e $28,6 \%$ apresentam de 10 ou mais concorrentes. Todas as startups relataram possuir concorrência, sendo que, para $57,1 \%$ das empresas, a concorrência é nacional; mas, para 14,3\%, a concorrência é exclusivamente internacional; porém, mista para $28,6 \%$.

Finalmente, foram mapeados os principais desafios encarados pelos empreendedores. Os cinco problemas mais relatados foram, em ordem decrescente: "capital inicial à disposição do negócio", "captação de clientes", "acesso aos financiamentos disponíveis no mercado", "escassez de investimentos" e "escalar as vendas". É interessante perceber que os obstáculos citados são diferentes e, em alguns momentos, opostos, como a falta de recursos iniciais aos fatores de extinção de empresas, como os encontrados por Nogueira e Arruda (2015).

\section{Considerações Finais}

A pesquisa permitiu identificar características das startups, evidenciando que, como a maioria dos seus CEOs está em sua primeira experiência empreendedora e se constituem de jovens empreendedores, é necessário um alto compromisso do ecossistema de inovação no suporte a esses empreendedores, de modo a acolher e prover informações e incentivos para o desenvolvimento dos CEOs e fomentar diversos encontros técnicos, com a intenção de compartilhar experiências, intercambiar conhecimentos práticos. Isso estimularia crescimento e amadurecimento dos empreendedores e direcionaria as atividades às necessidades individuais.

Nesse sentido, além do apoio geral, um dos respondentes sugeriu que o programa de aceleração poderia fomentar ações mais específicas ao negócio, apontando uma demanda de acompanhamento mais focado e menos generalista dos Programas que incubam ou aceleram iniciativas em estágio inicial. $\mathrm{O}$ apoio às startups, especialmente após o fim do processo de aceleração, é um ponto relevante e pode representar uma maneira de manter as relações entre a empresa e a aceleradora, monitorar seu desempenho e instigar o desenvolvimento empresarial.

Ao considerar a alta mortalidade das startups e a inquietação apresentada por um participante quanto ao futuro do empreendimento ao final do processo de aceleração, é percebida a ausência de indicadores de acompanhamento das empresas aceleradas edas hospedadas no Programa. Deste modo, faltam determinadas informações para adoção de medidas estratégicas, apoiadas pelo ecossistema de inovação, com o intuito de promover o sucesso dessas empresas recém aceleradas.

Os resultados apontam a predominância da formação em Ciência Exatas dos empreendedores, o que pode sugerir ao Ecossistema que estabeleça parceria com as Instituições de Ensino Superior para estimular o empreendedorismo em outras áreas do conhecimento. Ao mesmo tempo, esse achado pode estimular essas instituições a incluir disciplinas que discutam o empreendedorismo e a inovação ao longo da grade curricular nos cursos de graduação e de pós-graduação. Espera-se que isso possa contribuir para fomentar o 
espírito inovador, apresentando aos futuros entrantes no mercado de trabalho uma nova possibilidade de atuação no seu campo de conhecimento.

Depreende-se a partir dos dados que o Ecossistema de Inovação não deve somente promover a cultura do empreendedorismo desde as bases da formação escolar. É necessário analisar, de forma criteriosa e compreensiva, os desafios enfrentados pelos empreendedores, traduzindo as respostas em ação e mensurando indicadores de insucesso, visando elaborar políticas de redução e tratamento dos problemas encontrados pelas startups.

Levando-se em conta que o empreendimento mais "antigo" deste estudo surgiu em 2014, é possível afirmar que as startups estudadas são relativamente jovens, com menos de 4 anos, exigindo, por isso, um suporte maior do ecossistema de inovação, considerando que ainda se encontram em uma fase de alto índice de mortalidade (Nogueira, \& Arruda, 2015). O ecossistema deve prover suporte, apoio e respaldo a essas startups, estabelecendo políticas de incentivo, promovendo parcerias e investimentos na estrutura e buscando aumentar a capacidade em alavancar suas iniciativas.

Ademais, os empreendimentos pesquisados atuam em diversos segmentos e sua importância é ressaltada por tal característica, o que sugere a possibilidade de a inovação proposta melhorar o mercado em diversas áreas. Destaca-se ainda que, como a maioria dos produtos/serviços está em fase de venda, ainda que as empresas estejam em diversos estágios, é preciso que a aceleradora auxilie as startups no mapeamento dos clientes e na determinação de estratégias para vendas e para posicionamento no mercado. Essa situação é especialmente importante porque apenas metade delas possuem sócios com experiência em vendas.

Foi possível também identificar os desafios enfrentados pelos empreendedores. Estes podem ser divididos em fatores internos ("escalar as vendas" e "captação de clientes") e em fatores externos ("capital inicial à disposição do negócio", "acesso aos financiamentos disponíveis no mercado" e "escassez de investimentos"). Como se trata da percepção dos empreendedores é possível observar discrepância sem que haja invalidade de nenhum dos resultados, percebendo-se que são perspectivas diferentes e exigem uma postura colaborativa do ecossistema de inovação, em especial da aceleradora, no sentido de contribuir para a estruturação do modelo de negócio das startups e de fomentar o pensamento crítico sobre as estratégias a serem adotadas na fase inicial, considerando iniciativas para que se desenvolvam e superem os problemas, repensando-os de forma crítica e propositiva.

Os resultados apresentam pontos relevantes para o Ecossistema de Inovação Mineiro, destacando possíveis gargalos que precisam ser enfrentados pela parceria construída entre a iniciativa privada e a esfera pública, incentivando o desenvolvimento de startups. A baixa disponibilidade de investimento foi apontada como uma restrição a ser enfrentada por ações de fomento capazes de envolver governo e atrair investidores internos e externos, podendo ser exemplo deste gargalo. Desse modo, o estreitamento do diálogo entre startups e agentes do ecossistema de inovação pode permitir a adoção de projetos fiscais, jurídicos e administrativos que fomentem o empreendedorismo local.

Os desafios internos, relacionados às características do empreendimento, devem ser utilizados como base para elaboração de programas ou ações de qualificação do empreendedor, atuando ativamente na mitigação das fragilidades apontadas, usando métodos ágeis que visem aprimorar o preparo dos CEOs para os desafios do mercado. Esse tipo de iniciativa deveria envolver, desde Instituições de Ensino, incubadoras e/ou aceleradoras, programas de pré-aceleração, Centros de Empreendedorismo, até Governo e demais atores relevantes ao ecossistema de inovação que atuam diretamente com startups. 
A pesquisa permitiu também a identificação dos principais empecilhos externos ao processo de fomento à cultura da inovação e empreendedorismo, provendo subsídios para articulações político-econômicas que contribuam para o fortalecimento das inciativas estudadas. Os resultados geraram indícios que mostram que o Ecossistema de Inovação Mineiro deve empreender um grande esforço para garantir que as inovações geradas em Instituições de Ensino e instituições privadas sejam transformadas em negócios aplicados e sejam trabalhadas no mercado por meio de spin-offs.

Ainda em relação à necessária parceria e atuação do Governo, o ecossistema de inovação, em especial as organizações apoiadoras dos empreendimentos, como incubadoras e aceleradoras, precisariam agir insistentemente e continuamente frente às esferas governamentais, apresentando propostas de políticas e articulações embasadas em estudos com as principais demandas e propostas de redução dos problemas enfrentados pelas startups, criando um ambiente cada vez mais propício ao exercício do empreendedorismo.

$\mathrm{O}$ acesso a fontes de financiamento foi uma questão muito enfatizada nos questionários; porém, uma vez que isso não era objetivo do estudo, o instrumento de coleta não abordou fontes de investimento utilizadas ou buscou entender o que se refere à dificuldade de financiamento citada. Portanto, não há elementos que permitam a proposição de uma estratégia de negócio para solucionar esse problema. Esse é um ponto que pode gerar pesquisas futuras que tentem a municiar a elaboração de projetos para aprimoramento das políticas voltadas ao financiamento de empreendimentos inovadores, estabelecendo diretrizes de acesso mais flexíveis e adequadas à realidade desse tipo de negócio e incentivando, por meio de articulações político-econômicas, a atração de mais investidores.

\section{Referências}

Abernathy, W. J., \& Utterback, J. M. (1978). Patterns of Industrial Innovation. Technology Review, 80(7), 40-47. Disponível em: <http://www.academia.edu/download/50444122/Abernathy1978.pdf>. Acesso em: 19 de Julho de 2020.

Acs, Z. J., \& Amorós, J. E. (2008) Introduction: The Startup Process. Introduction: Estudios de Economía. 35(2), 121-132. Disponível em: <http://www.econ.uchile.cl/uploads/publicacion/867c6c35-923c-4251-8ce3-

9585eee8e443.pdf>. Acesso em: 19 de Julho de 2020.

Antunes, L. G. R., Araújo, G. S., \& Almeida, K. C. (2020). Estabelecendo o Modelo de Negócio de Incubadoras. Revista de Administração, Sociedade e Inovação, 6(1), 5-23. doi: https://doi.org/10.20401/rasi.6.1.318.

Armanios, D. E., et al. (2017). How Entrepreneurs Leverage Institutional Intermediaries in Emerging Economies to Acquire Public Resources. Strategic Management Journal, 38(7), 1373-1390.doi: 10.1002/smj.2575.

Associação Brasileira de Startups - ABSTARTUPS. Disponível em: <https://abstartups.com.br>. Acesso em: 16 de Novembro de 2017.

Cockayne, D. (2019). What is a Startup Firm? A Methodological and Epistemological Investigation into Research Objects in Economic Geography. Geoforum. doi: 10.1016/j.geoforum.2019.10.009. 
Cohen, S., Fehder, D. C., Hochberg, Y. V., \& Murray, F. (2019). The Design of Startup Accelerators. Research Policy, 48(7), 1781-1797.doi: 10.1016/j.respol.2019.04.003.

Cohen, S., \& Hochberg, Y. V. (2014). Accelerating Startups: The Seed Accelerator Phenomenon. In: Cohen, S., \& Hochberg, Y. V. (2014). Accelerating Startups: The Seed Accelerator Phenomenon. doi: 10.2139/ssrn.2418000.

Cohen, S. (2013). What do Accelerators do? Insights from Incubators and Angels .Innovations: Technology, Governance, Globalization, 8 (3-4), 19-25. Disponível em: <https://www.mitpressjournals.org/doi/pdf/10.1162/INOV_a_00184>. Acessoem: 19 de Julho de 2020.

Cusumano, M. A. (2013). Evaluating a Startup Venture. Communications of the ACM, 56(10), 26-29.

Del Sarto, N., Isabelle, D. A., \& Di Minin, A. (2019). The Role of Accelerators in Firm Survival: An FSQCA Analysis of Italian Startups. Technovation, 90. doi: 10.1016/j.technovation.2019.102102.

Dempwolf, C. S., Au, R, J., \& D'ippolito, M. (2014). Innovation Accelerators: Defining Characteristics Among Startup Assistance Organizations. SBA Office of Advocacy, Optimal Solutions Group, LLC, College Park.

Dolabela, F. (2008). O Segredo de Luísa - Uma Ideia, uma Paixão e um Plano de Negócios: Como Nasce o Empreendedor e se Cria uma Empresa. Rio de Janeiro: Sextante.

Dornelas, J. C. A. (2016). Empreendedorismo: Transformando Ideias em Negócios. $6^{\text {a }}$ Edição: Atlas.

Etzkowitz, H., \& Zhou, C. (2017). Hélice Tríplice: Inovação e Empreendedorismo Universidade-Indústria-Governo. Estudos Avançados, 31(90), 23-48. doi: 10.1590/s010340142017.3190003

Hunt, R. A. (2012). Entrepreneurial "Tweaking": An Empirical Study of Technology Diffusion through Secondary Inventions and Design Modifications by Start-Ups. Frontiers of Entrepreneurship Research, 32(15). doi:10.1108/14601061311324511.

Kohler, T. (2016). Corporate Accelerators: Building Bridges between Corporations and Startups. Kelley School of Business, Indiana University, Elsevier.

Kovács, I. (2003) Inovação Organizacional. In: Rodrigues, M. J., Neves, A., Godinho, M. M. (2003). (Org.) Para uma Política de Inovação em Portugal. Lisboa: Publicações Dom Quixote.

Kulchina, E. (2017). Do Foreign Entrepreneurs Benefit their Firms as Managers?Strategic Management Journal, 38(8), 1588-1607. doi: 10.1002/smj.2618.

Leung, A., Zhang, J., Wong, P. E., \& Foo, M. D. (2006). The Use of Networks in Human Resource Acquisition for Entrepreneurial Firms: Multiple "Fit" Considerations. Elsevier: Journal of Business Venturing, 21(5), 664-686.doi: 10.1016/j.jbusvent.2005.04.010.

Lins Filho, M. L., Andrade, A. P. V., \& da Silva, G. G. (2020). Capacidade de Inovar em Startups: Uma Abordagem sob a Ótica da Orientação para Aprendizagem. Revista de Gestão e Tecnologia (NAVUS), 10, 01-21. doi: 10.22279/navus.2020.v10.p01-21.1095. 
Machado, F. G. (2015). Investidor-Anjo: Uma Análise dos Critérios de Decisão de Investimento em Startups. Dissertação da Faculdade de Economia, Administração e Contabilidade da Universidade de São Paulo.

Matos, F. (2017). Qual a Região Campeã em Densidade de Startups no Brasil? O Estado de São Paulo, São Paulo/SP. Disponível em: < https://link.estadao.com.br/blogs/felipematos/qual-a-regiao-campea-em-densidade-de-startups-no-brasil-voce-vai-se-surpreender/> . Acesso em: 11 de outubro de 2019.

Mian, S., Lamine, W., \& Fayolle, A. (2016). Technology Business Incubation: An Overview of the State of Knowledge. Technovation. 50-51, 1-12. doi: 10.1016/j.technovation.2016.02.005.

Nogami, V. K. C. (2019). Destruição Criativa, Inovação Disruptiva e Economía Compartilhada: Uma Análise Evolucionista e Comparativa. Revista Suma de Negócios, 10(21), 9-16. doi:10.14349/sumneg/2019.V10.N21.A2.

Nogueira, V., \& Arruda, C. (2015). Causa da Mortalidade de Startups Brasileiras: O que Fazer para Aumentar as Chances de Sobrevivência no Mercado? Fundação Dom Cabral, DOM. Nova Lima, 9(25), 26-33. Disponível em: <https://www.fdc.org.br/conhecimento/publicacoes/artigo-29767>. Acesso em: 19 de Julho de 2020.

O’Connell, B. (2011). Start X: Training Ground for Stanford's Best and Brightest. Kauffman Foundation.

Perin, B. (2015). A Revolução das Startups: O Novo Mundo do Empreendedorismo de Alto Impacto. Alta Books; $1^{\mathrm{a}}$ Edição, Ebook.

Radojevich-Kelley, N., \& Hoffman, D. L. (2012). Analysis of Accelerator Companies: An Exploratory Case Study of their Programs, Processes, and Early Results. Small Business Institute Journal, 8(2), 54-70. Disponível <https://www.sbij.org/index.php/SBIJ/article/view/136>. Acesso em: 19 de Julho de 2020.

Ramírez, C. P., Moreno, A., Améstica, L., \& da Silva, S. S. (2019). Incubadoras en Red: Capital Relacional de Incubadoras de Negocios y la Relación com su Éxito. Revista de Administração, Sociedade e Inovação, $\quad 5(2), \quad 162-179 . \quad$ DOI: https://doi.org/10.20401/rasi.5.2.316

Reis, D. A., \& Gomes, I. M. A. (2017). Capital Humano, Intensidade da Inovação e Crescimento Econômico no Brasil. VIII International Symposium on Technological Innovation. Disponível em: <http://www.api.org.br/conferences/index.php/ISTI2017/ISTI2017/paper/viewFile/231/141<. Acesso em: 27 de Julho de 2020

Ries, E. (2011). The Lean Startup: How Today's Entrepreneurs Use Continuous Innovation to Create Radically Successful Businesses. Hardcover.

Salamzadeh, A., \& Kesim, H. K. (2015). Startup Companies: Life Cycle and Challenges. Proceedings of the IV International Conference on Employment, Education and Entrepreneurship (EEE), Belgrade/Serbia.

Santos, P. C. F. (2008). Uma Escala para Identificar Potencial Empreendedor. Tese de Doutorado da Universidade Federal de Santa Catarina. 


\section{SEBRAE. O que é uma Startup? Disponível em:} <https://www.sebrae.com.br/sites/PortalSebrae/sebraeaz/o-que-eumastartup,616913074c0a3410VgnVCM1000003b74010aRCRD>. Acesso em: 15 de Novembro de 2018.

Sousa, J. C., Júnior, L. A. F., \& Nobrega, K. C. (2020). Entrepreneurial Strategies and Innovative Strategies: Bibliometric Review, Concepts, Models and Future Investigations. Revista de Administração, Sociedade e Inovação, 6(2).doi: https://doi.org/10.20401/rasi.6.2.425.

Startup Brasil. Programa Startup Brasil. Disponível em: < https://www.startupbrasil.org.br/sobre_programa/>. Acesso em: 14 de janeiro de 2018.

Stayton, J., \& Mangematin, V. (2019). Seed Accelerators and the Speed of New Venture Creation. Journal of Technology Transference, 44, 1163-1187. doi: 10.1007/s10961017-9646-0.

Teixeira, A. A. C. (2007). Excesso de Incentivos à Inovação na Presença de Consumidores Sofisticados. Um Modelo de Progresso Tecnológico Endógeno com Capital Humano. Estudos Econômicos, 37 (3). doi: 10.1590/S0101-41612007000300006.

Vohora, A., Lockett, A., \& Wright, M. (2004). The Formation of High-Tech University Spinouts: The Role of Joint Ventures and Venture Capital Investors.The Journal of Technology Transfer, 29(3-4), 287-310. Disponível em: <https://link.springer.com/article/10.1023/B:JOTT.0000034124.70363.83>. Acesso em: $19 \mathrm{de}$ Julho de 2020.

Yin, R. K. (1994). Estudo de Caso: Planejamento e Métodos. Bookman Editora.

Weiblen, T., \& Chesbrough, H., W. (2015). Engaging with Startups to Enhance Corporate Innovation. California Management Review, 57(2), 66-90, University of California Press.doi: $10.1525 / \mathrm{cmr} .2015 .57 .2 .66$ 